Commonplace • Series 1.3: Global Transition to Open

\title{
A Platform is Not Enough: Examining the Relationship Between Library Publishing and Scholars of Color
}

Harrison Inefuku

Published on: Nov 16, 2021

DOI: $10.21428 / 6 \mathrm{ffd} 8432.22686 \mathrm{aOC}$

License: Creative Commons Attribution 4.0 International License (CC-BY 4.0). 
As libraries have championed open access as a way to liberate knowledge from the financial barriers that restrict access to scholarship, library-based publishing has emerged as a site of intervention for many academic libraries. 1 In publishing open access scholarship, often at no cost to authors, libraries provide an alternative to commercial publishers that charge exorbitant subscription fees, article processing charges, or both.

The discourse around open access, however, has largely focused on eliminating financial barriers to access. This colorblind approach to transforming scholarly communications fails to consider the obstacles faced by those seeking to publish knowledge by and about communities of color.

As library publishing programs are generally subsidized by their host libraries and free from profit-making considerations, Charlotte Roh and I have argued that libraries are well positioned to, "ensure that a wide range of voices and perspectives can access the scholarly record." 2 This sentiment is echoed in the Library Publishing Coalition's Ethical Framework for Library Publishing:

As a developing sector of publishing, library publishers have the ability to intervene and reduce the impact of bias in content selection and create hospitable environments for a diversity of identities, viewpoints, and approaches. $\underline{3}$

What does it mean for library publishers to create hospitable environments for a diversity of identities, viewpoints, and approaches? In 2020, in the wake of the murder of George Floyd and the increase in attacks on Asian Americans, many libraries and library associations released statements proclaiming a commitment to anti-racism. How can those of us engaged in library publishing use our roles to support these goals? How can libraries reallocate collections spending to transform scholarly communications so it is inclusive and operates with anti-racist and anti-oppressive principles?

\section{Interrogating our Intentions}

Before looking to publish the knowledge of communities of color, library publishing programs first need to interrogate their intentions. Is there an authentic interest in working with and uplifting communities of color, or are they driven by virtue signaling and tokenism? Are library publishing programs an appropriate venue for publishing 
their knowledge? As Tamar Evangelista-Dougherty notes, "performative DEI" causes harm as well:

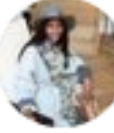

\section{What about the people who hide behind "performative DEI" initiatives? They cause almost as much harm as those who are openly against antiracist efforts. Watching antiracist podcasts, reading Ibram X. Kendi books, and recruiting more POC's will not end systemic racism in your org.}

Publishing the knowledge of communities of color must be grounded in relationshipbuilding. As Gregory Younging writes in Elements of Indigenous Style:

In Indigenous publishing, you have to build your trust out of relationship, not just out of a contract. The Indigenous cultural imperatives of truthfulness, honesty, mindfulness about community impacts, and continuity with history and heritage apply to everyone working to write, edit, and publish Indigenous content. $\underline{4}$

Have our publishing programs, libraries, and universities developed relationships with the communities whose knowledge we seek to publish? Many of our universities have histories of excluding and marginalizing communities of color: this is true for my employer, Iowa State University. As a public, predominantly white, and land-grant university, Iowa State is inextricably linked to the silencing, marginalization, and exploitation of communities of color in American society. For example:

- Iowa State is built on profits gained from land taken from indigenous communities, as detailed in the Land-Grab Universities project. Meanwhile, our official land acknowledgment centers the university, rather than those communities whose land our university occupies.

- Iowa passed and signed into law House File 802 in 2021, limiting the ways in which the histories and current realities of racism and oppression can be taught on campus.

What does it mean for library publishing programs to publish the knowledge of communities of color and how can we ensure that these programs don't continue to 
replicate an exploitative relationship with communities of color? Providing scholars of color access to a publishing platform is not enough.

\section{Ways Forward}

\section{Offer Support Services}

One way is to reallocate collections spending to support scholars of color who partner with library publishing programs. Many library publishing programs do not offer the same level of support as commercial publishers and university presses, including developmental editing, copyediting, typesetting, and journal management/administration. At many library publishers, these tasks fall on journal editors or authors. $\underline{5}$ This expectation of editors and authors creates an additional burden for scholars of color who already overburdened with service work. By providing this support for publications dedicated to sharing the knowledge of communities of color, library publishing programs would allow scholars to focus on their research, writing, and management, rather than the technical aspects of publication. Providing language editing and translation services can help English L2 and international authors publish through library publishing programs.

Providing professional copyediting and typesetting services can also help scholars of color in tenure and promotion process, which often devalues their scholarship. In 2020, Dr. Paul Harris was denied tenure by the University of Virginia. One reason given for the denial was Harris's publication in Journal of African American Males in Education-a publication that his committee felt "appeared to be self-published," despite a $20 \%$ acceptance rate. $\underline{6}$ JAAME is an open access journal published on Scholastica, a platform also used by some library publishing programs. As work by and about communities of color often faces heightened scrutiny within academia, faculty of color shouldn't have to worry about whether their publication venues appear "professional enough" to pass muster with their white colleagues.

\section{Compensate}

To end the cycle of knowledge exploitation, libraries should also compensate scholars of color for their knowledge and labor. The work involved in writing, reviewing, and editing must be recognized and valued-a line on a CV is not reward enough. This is being done by up//root: a We Here publication, which provides "a space for Black and Indigenous folks, and People of Color (BIPOC) to share their research and meditations 
on their knowledge, experiences, and ways of being in libraries and archives." As stated by founding editors Joyce Gabiola, Sofia Leung, and Jorge López-McKnight:

In an emancipatory spirit, it is our intention through this endeavor to build and sustain a media space that unapologetically centers, uplifts, and financially compensates for the research and creative works of Black, Indigenous, and Persons of Color. $\underline{7}$

up//root is a project of emancipation-published independently by We Here, that only publishes authors who identify as BIPOC and requires the exclusive citation of BIPOC authors. Library publishers should also provide publications the freedom to experiment, innovate, and create publication venues that center and uplift marginalized voices.

\section{Reducing Harm}

In outlining their peer review process, The Critical Social Educator (TCSE) writes:

We maintain that academic publishing's "blind review" process embodies this privileged irresponsibility in that its ableist language and rules grants unequal power to reviewers and editors. The dominant peer review protects reviewers and editors while leaving authors vulnerable to harm. $\underline{8}$

TCSE, which is published through the Iowa State University Library's Digital Press, employs an open peer review process that promotes "collegiality and a nurturing publishing environment" and engages both education scholars and practitioners. The focus on collegial and nurturing peer review publishing processes is important for scholars of color, whose work is often over-scrutinized and devalued in editorial and peer review and copyediting. In publishing the work of scholars of color, libraries need to ensure that our publication processes do not perpetuate this harm-something that scholars of color submitting to library and information science publications have experienced.

There are too many examples of how library and information science publications have harmed scholars and communities of color. Christian I.J. Minter writes of her experience submitting an invited editorial on anti-Blackness in librarianship to the Journal of the Medical Library Association, "It was obvious the copy editor did not have sufficient knowledge of the subject matter to engage in a fruitful conversation about the thoughtful and intentional choices we made in our writing." $\underline{9}$ The copyeditor resisted the authors' pushback on edits that changed the meaning and impact of the 
editorial, insisting on adherence to the MLA style guide and negating the knowledge and perspective of the authors. The journal's editors failed to step in until the authors decided to withdraw the editorial.

\section{Embarking on this Work}

Libraries need to ensure that their publishing programs don't continue to harm authors of color. Services, workflows, and policies need to be evaluated to identify how they may negatively impact scholars of color. Before embarking on this work, libraries must ensure that they hold the knowledge and capacity to do the work. Do library staff engaged with publishing:

- Engage in education and critical self-reflection on diversity, inclusion, and social justice?

- Understand how systemic racism impacts scholarly communication and publishing?

- Engage in community with marginalized groups on campus?

- Participate in anti-racist and anti-oppressive efforts on campus?

- Represent the marginalized communities whose knowledge we seek to publish?

- Work with service providers of color and vendors who value and enact anti-racist and anti-oppressive practices? $\underline{10}$

Even if library publishing programs aren't the appropriate sites to publish the knowledge of communities of color, or are not yet ready to commit to and engage in the work, libraries can still support the efforts by sponsoring initiatives that seek to make scholarly communications more inclusive, like becoming a partner of the Coalition for Diversity and Inclusion in Scholarly Communications (C4DISC). Libraries and library organizations can also support publications that are published independently or hosted elsewhere, following the lead of the Scholarly Publishing and Academic Resources Coalition (SPARC). In 2020, SPARC provided We Here with a $\$ 20$, 000 grant to support the publication of up//root, without any limitations on how the funds can be used. With the grant, We Here intends to "compensate contractors of up//root for their time and labor, including the Editorial Team of five (including two students), peer reviewers, and contributors."

With many libraries investing in programs and initiatives that seek to transform scholarly communications, it is also imperative that libraries support efforts aimed at eliminating systemic racism and oppression in scholarly communications and publishing, whether through building anti-racist and anti-oppressive library publishing 
programs or sponsoring external organizations who are working to create real change. For libraries who espouse a commitment to diversity, equity, and inclusion, working to center voices of color in the scholarly record cannot be considered a special project or additional work-it must be viewed as an integral aspect of the library's mission. If libraries truly stand behind the anti-racism statements they've released, then they need to put in the resources necessary to uplift communities of color.

\section{Footnotes}

1. While library publishing programs exist globally and in a range of library types, I am focusing here on academic libraries in the United States. $\subseteq$

2. Harrison W. Inefuku and Charlotte Roh, "Agents of Diversity and Social Justice: Librarians and Scholarly Communication," in Open Access and the Future of Scholarly Communication: Policy and Infrastructure, edited by Kevin L. Smith and Katherine A. Dickson (Lanham, MD: Rowman and Littlefield, 2016), 107-128. 3. Library Publishing Coalition Ethical Framework Task Force, "Diversity, Equity, and Inclusion" in An Ethical Framework for Library Publishing (Atlanta: Library Publishing Coalition, 2018), https://librarypublishing.org/resources/ethicalframework/ethical-framework-diversity $\perp . \oplus$

4. Gregory Younging. Elements of Indigenous Style: A Guide for Writing By and About Indigenous Peoples. Edmonton: Brush Education, 2018. 44.

5. See, for example, the workflows provided through the Library Publishing Coalition's Library Publishing Workflows project. $\_$

6. Taylor Harris, “Whiteness Can't Save Us," Catapult (June 10, 2020), https://catapult.co/stories/taylor-harris-on-police-violence-racism-church-parentingblack-kids. $\doteq$

7. Joyce Gabiola, Sofia Leung, and Jorge López-McKnight, “Editorial Launch of up//root," up//root (February 7, 2021), https://www.uproot.space/features/editoriallaunch..

8. The Critical Social Educator. "Submission and Peer Review Process." https://www.iastatedigitalpress.com/tcse/site/peerreview/. $\doteq$

9. Christian I. J. Minter, "A Case Study on Anti-Black Publishing Practices," December 11, 2020, https://christianminter.com/2020/12/11/a-case-study-on-anti- 
black-publishing-practices/..

10. The Editors of Color database allows searching by areas of expertise, genre, and types of media, among other facets. $\_$ 